\title{
Bucle multidisciplinar para la sustentabilidad urbana
}

\author{
Multidisciplinary loop for urban sustainability \\ Circuito multidisciplinar para a sustentabilidade urbana
}

\section{Luis Fernando Molina-Prieto Mónica Suárez-Serrano María Eugenia Villa-Camacho Universidad de América, Bogotá (Colombia)}

Molina-Prieto, L., Suárez-Serrano, M., \& Villa-Camacho, M. (2019). Bucle multidisciplinar para la sustentabilidad urbana. Revista de Arquitectura (Bogotá), 21(2), 76-88. doi: http://dx.doi.org/10.14718/RevArq.2019.21.2.2048

\section{Luis Fernando Molina-Prieto}

Arquitecto, Universidad Nacional de Colombia, Bogotá (Colombia)

Maestría (c) en Gestión ambiental urbana, Universidad de América, Bogotá (Colombia).

(D) https://orcid.org/0000-0002-3039-427X

Imolinaprieto@gmail.com

Mónica Suárez-Serrano

Ingeniera industrial, Universidad Distrital, Bogotá (Colombia)

Especialización y máster en Gestión en redes de valor y logística, Universidad Piloto de Colombia, Bogotá (Colombia)

(D) https://orcid.org/0000-000I-5590-5227

monica.suarez@investigadores.uamerica.edu.co

\section{María Eugenia Villa-Camacho}

Psicóloga, Pontificia Universidad Javeriana, Bogotá (Colombia).

Máster en Ciencias Contables, Universidad de la Salle, Bogotá (Colombia). MBA, Universidad de la Salle, Bogotá (Colombia).

Doctora en Administración, Universidad de San Pablo CEU, Madrid (España). (D) https://orcid.org/0000-0003-0327-9425

\section{Resumen}

El crecimiento acelerado de la población urbana genera problemas ambientales, económicos y sociales en los que se reconocen los inputs que requieren los procesos urbanos para su normal funcionamiento (energía, materiales y agua) en aspectos industriales, económicos y humanos. Asimismo, se identifican los outputs generados en la producción de bienes o servicios, los cuales originan una serie de externalidades no deseadas. La metodología contó con un trabajo interdisciplinar organizado en cuatro momentos: planeación, revisión bibliográfica, interpretación de los resultados y formulación. Como resultado se presentan ocho conceptos que fortalecen la sustentabilidad urbana: ciclo cerrado, metabolismo urbano, economía circular, ecología industrial, red de valor, logística inversa, psicología ambiental y ecodiseño, a partir de los cuales se generó la propuesta de un modelo multifactorial para el fortalecimiento de la sustentabilidad' urbana. Se concluye que para alcanzar la sustentabilidad urbana urge crear vasos comunicantes entre las disciplinas que inciden de manera directa en las dinámicas que dan vida a las ciudades contemporáneas.

Palabras clave: ciudades resilientes; desarrollo inclusivo; desarrollo urbano sustentable; gestión ambiental urbana; planificación urbana; psicología ambiental.

\section{Abstract}

Accelerated growth of the urban population creates environmental, economic, and social problems, in which inputs require urban processes for their normal functioning (energy, materials, and water), in industrial, economic, and human aspects. Additionally, the outputs generated in the production of goods and services are recognized, which create a series of undesired externalities. The methodology included interdisciplinary work, divided into four phases: planning, literature review, interpretation of the results, and formulation. As a result, we present eight concepts that strengthen urban sustainability: closed loop, urban metabolism, industrial ecology, circular economy, value network, inverse logistics, environmental psychology, and eco-design, upon which a proposal to strengthen urban sustainability through a multifactorial model was created. The article concludes that to achieve urban sustainability, it is necessary to create connecting vessels between disciplines that directly affect the dynamics that give life to contemporary cities.

Keywords: Resilient cities; inclusive development; sustainable urban development; urban environmental management; urban planning; environmental psychology.

\section{Resumo}

O crescimento acelerado da população urbana gera problemas ambientais, econômicos e sociais nos quais são reconhecidos os inputs que requerem os processos urbanos para seu normal funcionamento (energia, materiais e água) em aspectos industriais, econômicos e humanos. Além disso, são identificados os outputs gerados na produção de bens ou serviços, os quais originam externalidades não desejadas. A metodologia contou com um trabaIho interdisciplinar organizado em quatro momentos: planejamento, revisão bibliográfica, interpretação dos resultados e formulação da proposta do circuito multidisciplinar. Como resultado, são apresentados oito conceitos que fortalecem a sustentabilidade urbana: ciclo fechado, metabolismo urbano, economia circular, ecologia industrial, rede de valor, logística reversa, psicologia ambiental e ecodesenho, a partir dos quais foi gerada a proposta de um modelo multifatorial para fortalecer a sustentabilidade urbana. Conclui-se que, para atingir a sustentabilidade urbana, é urgente criar vínculos entre as disciplinas que afetam, de maneira direta, as dinâmicas que dão vida às cidades contemporâneas.

Palavras-chave: cidades resilientes; desenvolvimento inclusivo; desenvolvimento urbano sustentável; gestão ambiental urbana; planejamento urbano; psicologia ambiental. 


\section{Introducción}

El artículo hace parte de los resultados del proyecto de investigación "Diseño de una red de valor de ciclo cerrado para poner a disposición de la industria manufacturera de Bogotá", avalado y financiado por la Fundación Universidad de América, y que se realiza en el marco de tres grupos de investigación de dicha universidad: "Territorio y habitabilidad"1, "Logística"2 y "Gestión y competitividad de las organizaciones" ${ }^{\prime \prime}$. El proyecto, iniciado en enero de 2018, y que se extendió hasta diciembre del mismo año, se fundamenta en un modelo multifactorial cuyo objetivo es el fortalecimiento de la sustentabilidad urbana, por lo cual se presenta la propuesta: Bucle multidisciplinar para la sustentabilidad urbana.

El crecimiento acelerado de la población urbana ha generado graves problemas ambientales, económicos y sociales a nivel global. Ambientales: degradación de ecosistemas y pérdida de biodiversidad por residuos contaminantes urbanos; generación de gases de efecto invernadero; incremento del cambio climático y sus repercusiones; impacto negativo en la salud humana (Fernández, 2011). Económicos: aumento de la pobreza

1 Luis Fernando Molina-Prieto.

2 Mónica Suárez-Serrano.

3 María Eugenia Villa-Camacho. urbana; desempleo; bajos niveles de educación; mayores tasas de delincuencia e inseguridad (Rucks-Ahidiana y Harding, 2015). Sociales: exclusión social; segregación y marginalidad espacial; fragmentación urbana; inequidad social; polarización social (Musterd y Ostendorf, 2013).

En 2017, la población mundial alcanzó los seis mil seiscientos millones de habitantes, y para 2030 se espera que supere los ocho mil quinientos (United Nations, 2017). En 2014, el $54 \%$ de la población del planeta habitaba en las ciudades, en diversas proporciones, que dependen de la región: en Norte América el $82 \%$; en América Latina el $80 \%$; en Europa el $73 \%$; en Asia el $48 \%$ y en África el $40 \%$ (United Nations, 2014). Con respecto a Colombia, el Banco Mundial reportó en 2017 que la población urbana correspondía al $77 \%$.

\section{Inputs}

Para su normal funcionamiento, las ciudades requieren enormes cantidades de energía, materiales y agua, recursos que, en su mayoría, son finitos. La energía es necesaria para el transporte, la industria, el comercio, las edificaciones, la infraestructura, la distribución de agua y la producción alimentaria. A nivel global, las ciudades consumen el $75 \%$ de la energía total generada (UN-Hábitat, 2012), pero, de acuerdo con características

\begin{tabular}{|c|c|c|c|c|c|}
\hline \multirow[b]{2}{*}{ Ciudad } & \multirow[b]{2}{*}{ Año } & \multicolumn{4}{|c|}{ Energía consumida } \\
\hline & & Residencial & $\begin{array}{l}\text { Industria y } \\
\text { comercio }\end{array}$ & Transporte & Total \\
\hline Filadelfia & 2015 & 51.582 .023 & 69.860 .346 & 28.098 .920 & 149.541.289 \\
\hline Las Vegas & 2014 & 23.130 .376 & 64.842 .663 & 93.025 .588 & 180.998 .626 \\
\hline Nueva York & 2014 & 363.383 .312 & 460.081 .837 & 136.109.809 & 959.574 .958 \\
\hline Washington D.C. & 2013 & 17.263 .134 & 48.698 .452 & 22.710 .208 & 88.671 .793 \\
\hline
\end{tabular}

\section{Tabla 1. Energía consumida en cuatro ciudades de Estados Unidos (en MMBtu*) \\ Fuente: elaboración propia a partir de American Council for an Energy-Efficient Economy-ACEEE (2017) \\ *MMBtu = un millón de Btu. Btu $=$ British Thermal Unit}

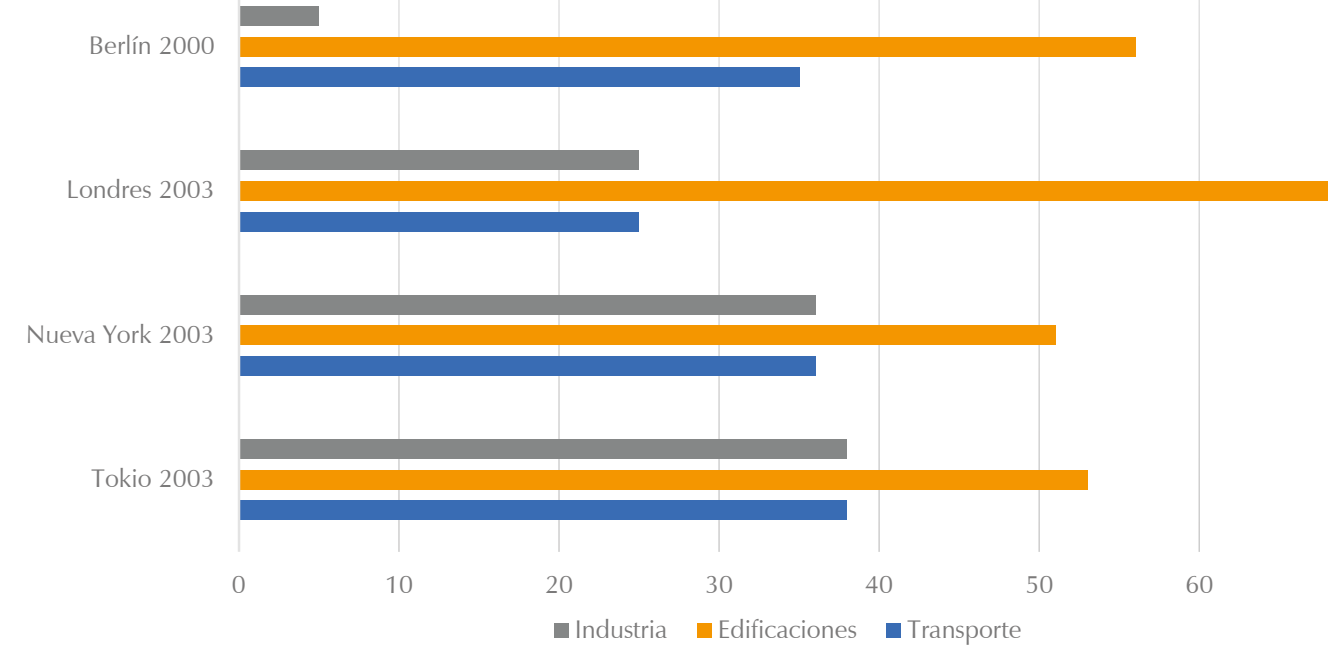

8igura 1. Energía consumida en cuatro ciudades de países desarrollados (en \%) Fuente: elaboración propia a partir de United Nations (2008).

This article is available in English on the website of Revista de Arquitectura (Bogotá) http://dx.doi.org/10.14718/RevArq.2019.21.2.2048 
$>$ Figura 2. Energía consumida en cuatro ciudades de países de ingresos medios (en \%)

Fuente: elaboración propia a partir de United Nations (2008). $\rightarrow$ Figura 3. Energía consumida en tres megaciudades asiáticas (en \%)

Fuente: elaboración propia a partir de United Nations (2008).
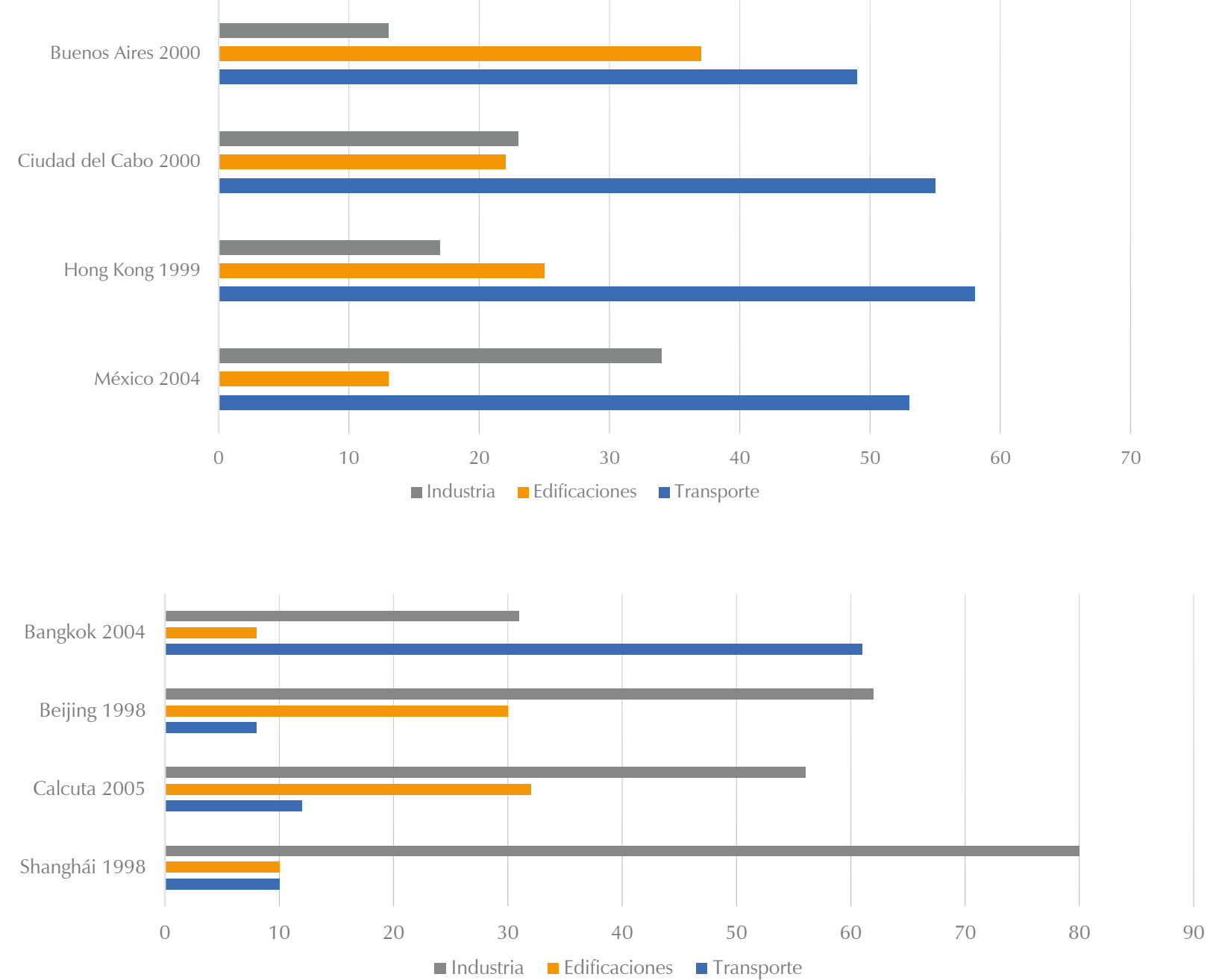

propias como la dimensión, la extensión, la población y el nivel de desarrollo, cada ciudad requiere una cantidad de energía particular, la cual es consumida en distintas proporciones por los tres principales sectores urbanos: edificaciones, industria y transporte (Tabla 1).

En las ciudades de los países desarrollados, más de la mitad de la energía es consumida para el funcionamiento y el mantenimiento de la infraestructura edificada, cerca de un $30 \%$ por el transporte, y el resto por la industria (Figura 1). Según Alfonso y Pardo (2014), Bogotá -la capital de un país en desarrollo-, consumió un total de 183.715.392 MMBtu de energía en 2010, un poco más que la energía consumida por Las Vegas en 2014.

En las ciudades de economías medias, más de la mitad de la energía es consumida por el transporte, el resto se distribuye -en diversas proporciones- entre las edificaciones y la industria (Figura 2).

En las megaciudades de los países en desarroIlo, como China o India, la industria consume hasta un $80 \%$ de la energía (Figura 3).

De otro lado, los principales materiales que requieren las ciudades son: biomasa para la provisión de alimentos y para la producción de algunos productos de origen orgánico; combustibles fósiles -carbón, petróleo y gas natural- para generar energía; minerales metálicos y no metálicos para la industria; materiales para la industria de la construcción: arena, piedra, arcilla e insumos para el cemento (Schaffartzik et al., 2014).

De acuerdo con Franke, Busch y Zeitz (s. f.), las sociedades agrarias consumían principalmente materiales orgánicos (biomasa) para alimentación, leña y refugio. Pero con la evolución de las civilizaciones no solo cambiaron los materiales requeridos por las ciudades, sino que se multiplicaron las cantidades demandadas. Según Schaffartzik et al. (2014), la transición global de las sociedades agrarias a los regímenes industrializados está vinculada a la explotación masiva de los recursos naturales, al punto que, actualmente, la humanidad usa aproximadamente 68 gigatones-GT ${ }^{4}$ de materiales por año, diez veces más que cien años atrás. En los últimos setenta años la extracción de materiales para las ciudades creció a un ritmo exponencial, especialmente en Asia y América Latina (Figura 4). Con respecto a Bogotá, en 2010 se consumieron en la ciudad un total de 2900 millones de toneladas de biomasa (alimentos) y 6 millones de toneladas de materiales de construcción (Alfonso y Pardo, 2014).

En lo concerniente a las necesidades anuales de agua, Nueva York se destaca a nivel mundial con 10,9 millones de megalitros ${ }^{5}-\mathrm{ML}$, seguida por Guangzhou con 9,8 millones, Shanghái con 7,5 millones, Los Ángeles con 6,6 millones, Tokio

\footnotetext{
41 gigatón $=$ mil millones de toneladas.

5 Un megalitro $(\mathrm{ML})=$ un millón de litros de agua.
} 

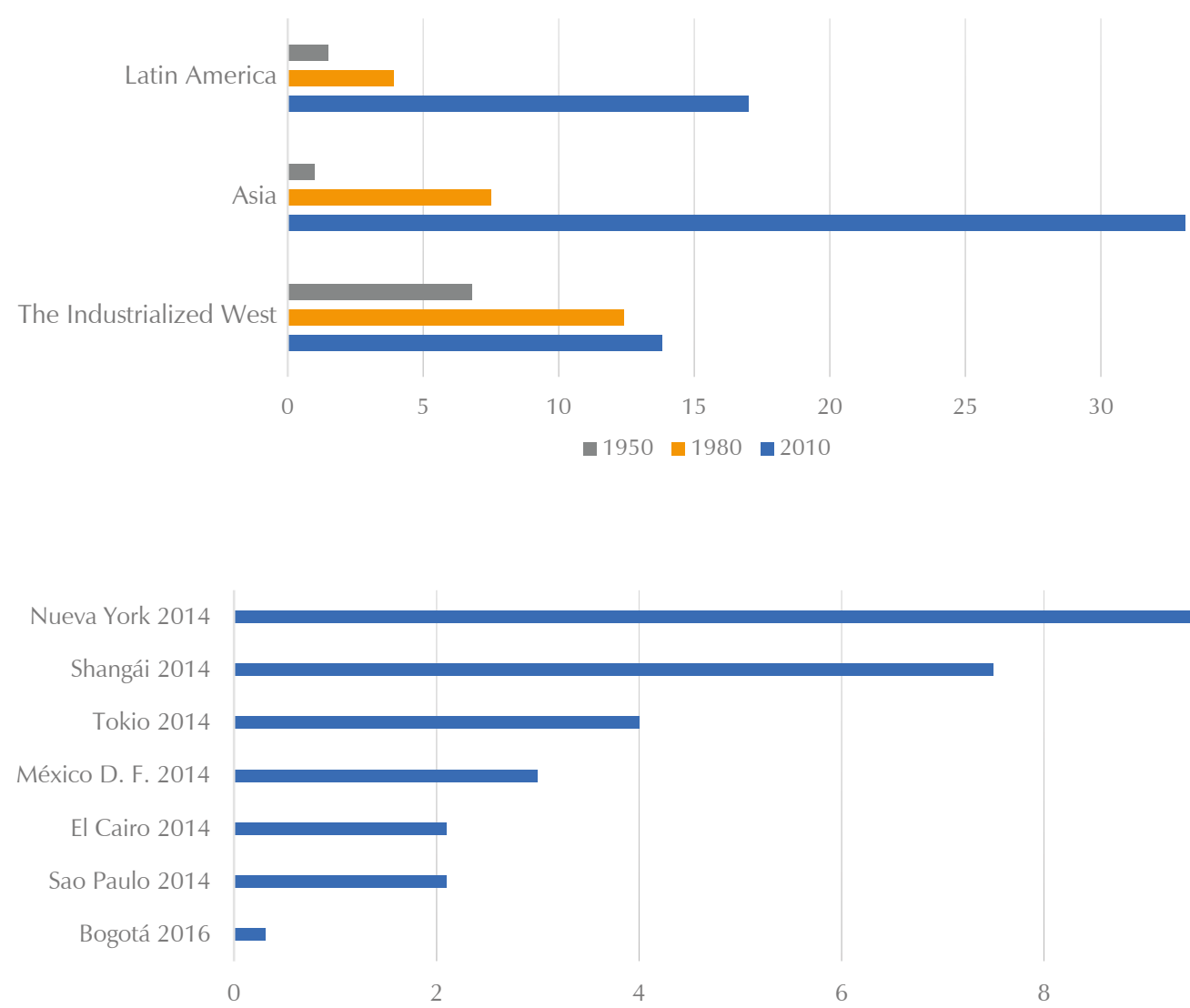

4

- Millones de megalitros

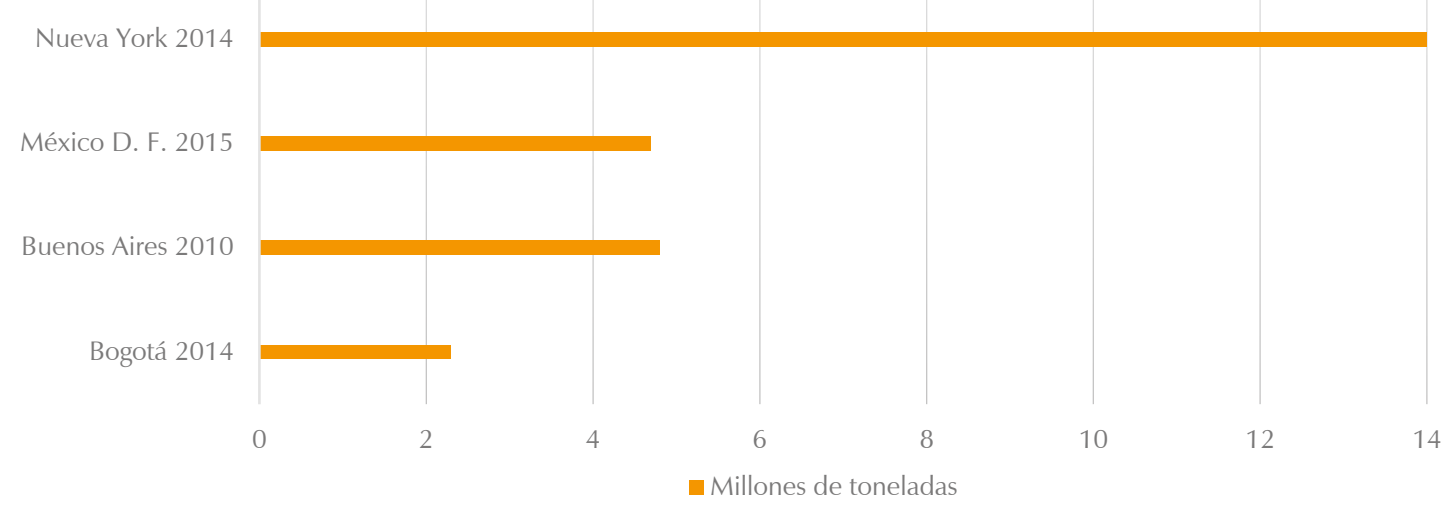

( Figura 4. Consumo de materiales domésticos por región (en gigatones por año) Fuente: elaboración propia a partir de Schaffartzik et al. (2014)
- Figura 5. Comparativo: consumo de agua en siete ciudades

Fuente: elaboración propia a partir de Kennedy et al. (2015) y Jiménez y Santana (2017) con 4 millones, Mumbai con 3,9 millones, México D. F. con 3 millones, Beijing con 2,9 millones, Seúl con 2,7 millones, Osaka con 2,5 millones, Buenos Aires con 2,2 millones, El Cairo con 2,1 millones y São Paulo con 2,1 millones. El resto de las ciudades del mundo consumen, cada una, menos de 2 millones de ML por año (Kennedy et al., 2015). De acuerdo con funcionarios de la Empresa de Acueducto y Alcantarillado de Bogotá, en 2016 se realizó una provisión neta real de agua de 110 litros por habitante/día (Jiménez y Santana, 2017), es decir, la ciudad consumió ese año 0,321 millones de ML (Figura 5).

\section{Outputs}

La energía, los materiales y el agua son transformados en las ciudades para generar bienes o servicios que permitan mantener el normal funcionamiento de la vida urbana. Pero, al transformarlos, se generan una serie de externalidades no deseadas: i) emisiones contaminantes generadas por fuentes fijas y móviles; ii) residuos sólidos (orgánicos e inorgánicos) resultantes de procesos industriales, comerciales y residenciales; iii) escombros generados por la industria de la construcción o por demolición de edificaciones obsoletas; y iv) residuos líquidos provenientes de la industria, la vivienda, el comercio y otras actividades, como las recreativas o las educativas.

En directa relación con las características de cada ciudad -dimensión, extensión, población y nivel de desarrollo--, se genera una cantidad específica de externalidades. Por ejemplo: en lo concerniente a las emisiones de efecto invernadero, Nueva York originó el equivalente a 55 millones de toneladas de $\mathrm{CO}_{2}$ en 2011; México D.F. 30,7 millones en 2012; Buenos Aires 15,6 millones en 2008 y Bogotá 6,7 millones en 2014. En cuanto a residuos sólidos, Nueva York produjo 14 millones de toneladas en 2014; México D.F. 4,7 millones en 2015; Buenos Aires 4,8 millones en 2010 y Bogotá 2,3 millones en 2014 (Figura 6). Además, Bogotá generó 223 millones de metros cúbicos de \&igura 6. Comparativo: producción de residuos sólidos en cuatro ciudades Fuente: elaboración propia a partir de varias fuentes (2018). 
aguas residuales en 2014, y 12 millones de toneladas de escombros ese mismo año (Gobierno de la Ciudad de Buenos Aires, 2009; González, 2010; City of New York, 2011; Gobierno de la Ciudad de México, 2012, 2015; Alfonso y Pardo, 2014).

Teniendo en cuenta que la explotación masiva de los recursos naturales es totalmente insustentable, puesto que el sistema mundo está confinado a un área limitada y, por ende, es finito; y considerando que el vertimiento de gases contaminantes en la atmósfera; el derrame de residuos líquidos en lagos, ríos y océanos, y la descarga de residuos sólidos en la biósfera es perjudicial no solo para los ecosistemas y la biodiversidad, sino además para la especie humana, -el artículo propone el modelo de Bucle multidisciplinar para la sustentabilidad urbana.

\section{Metodología}

La investigación contó con cuatro momentos: i) elaboración del modelo de procedimiento, establecimiento de la ventana de tiempo, selección de muestra e instrumento de análisis: se estableció como modelo de procedimiento la revisión sistemática de libros y artículos científicos; se fijó una ventana de tiempo que inicia con la primera revolución industrial en el siglo XVIII -porque con ella empezó la explotación masiva de los recursos naturales para abastecer las nacientes ciudades industriales, al tiempo que se vertían en el ambiente enormes cantidades de externalidades producto de los procesos industriales y urbanos- y se extiende hasta el 2017; se estableció una ciudad para realizar el muestreo -datos concernientes a requerimientos de energía, materiales y agua, así como a la generación de externalidades-: Bogotá, por ser la ciudad sobre la cual se centran los objetivos de la investigación; y se dispuso el análisis comparativo como instrumento de análisis; ii) obtención de conocimiento sobre el objeto de estudio: se realizó una búsqueda sistemática ${ }^{6}$ de propuestas teóricas cuyo objetivo fuese el fortalecimiento de la sustentabilidad urbana -en correspondencia con la ventana de tiempo previamente definida-, haciendo énfasis en las que buscan reducir la demanda de energía, materiales y agua por parte de las ciudades, así como las que pretenden minimizar la producción de externalidades negativas; iii) análisis de la información e interpretación de los resultados; y iv) formulación de la propuesta Bucle multidisciplinar para la sustentabilidad urbana.

6 Dos directrices conceptuales establecidas por las Naciones Unidas nos orientaron en dicha búsqueda: "Para cumplir con los estándares mínimos de residuos, las ciudades deben cumplir con dos requisitos previos: minimización del uso de combustibles fósiles e insumos materiales; y la maximización del reciclaje y la reutilización de energía, agua y materiales" (United Nations, 2008, p. 156).

\section{Resultados}

Si bien la investigación fue formulada desde tres disciplinas principales -arquitectura, ingeniería industrial y psicología-, no se establecieron limitantes frente a otros campos de conocimiento: se adelantó una exploración en diversos campos disciplinares, interdisciplinares y multidisciplinares. Tras dicha indagación, se seleccionaron ocho conceptos teóricos ${ }^{7}$ que surgieron de las matemáticas y la geometría, la teoría de grafos, la teoría de sistemas, las ciencias de la salud, la ingeniería sanitaria, el urbanismo, la planificación urbana, la ingeniería industrial, la ecología, la economía, el diseño industrial, el comercio, la psicología y la arquitectura, entre otras disciplinas, los cuales se presentan a continuación en orden cronológico a partir de su fecha de concepción. De cada uno de ellos se esboza una sucinta descripción de sus orígenes y evolución.

\section{Ciclo cerrado}

El concepto de ciclo cerrado surgió en los fértiles campos de la matemática y la geometría del siglo XVIII. Fue el suizo Leonard Euler quien propuso en 1735 un circuito o "camino cerrado", que recorre cada arista de un polígono establecido, exactamente una vez, para dar respuesta al famoso problema de los puentes de Königsberg ${ }^{8}$, y crea de manera paralela la teoría de grafos. Más recientemente, la teoría de sistemas, planteada por Bertalanffy (1993), formuló dos tipos de sistemas: los abiertos y los cerrados. La termodinámica se aplica específicamente sobre los cerrados.

El concepto de ciclo cerrado (closed loop) se aplica actualmente a incontables campos disciplinares: robótica, informática, inteligencia artificial, medicina, confort térmico, ventilación mecánica, control termodinámico y redes de valor, entre otras. Según Guide y van Wassenhove (2009), a mediados de la década de los noventa se establecieron los fundamentos del concepto de ciclo cerrado en el campo de la ingeniería industrial, y desde entonces se aplican a una variedad de actividades de recuperación: adquisición de productos usados, logística inversa, remanufactura, reparación y re-marketing, entre otras. Estos autores proponen cinco fases en la evolución del concepto y su aplicación en la ingeniería industrial: i) la era dorada de la remanufactura, que tuvo su auge en

\footnotetext{
7 Se seleccionaron estos ocho conceptos porque tienen como objetivos: i) la reducción de extracción de materiales naturales; ii) la reducción de externalidades; y, además, porque han generado un amplio y vigente corpus investigativo que se refleja en innumerables libros, tesis y artículos científicos.

8 En el siglo XVIII, la ciudad de Königsberg -perteneciente a Prusia Oriental por aquella época- estaba surcada por el río Pregel, y contaba con siete puentes para cruzarlo. Durante décadas los habitantes de la ciudad intentaron encontrar una ruta que, cruzando una sola vez cada puente, regresara al punto de partida (Núñez, Alfonso, Bueno, Diánez y Olivenza, 2004).
} 
los primeros años de la década de los noventa; ii) de la remanufactura a la valoración de la logística inversa, que cobró importancia durante los primeros años del presente siglo y contribuyó de manera fundamental a la solución de una serie de problemáticas económicas y ecológicas; iii) coordinación de la cadena de suministro inversa, que proporcionó una mayor comprensión para el diseño de los canales descendentes y ascendentes, permitió tomar mejores decisiones en el flujo de productos "aguas arriba", facilitó la interacción entre productos nuevos y remanufacturados, y redujo las tasas de retorno de los clientes de primer nivel; iv) Cerrando el ciclo, perspectiva de diseño integrado que tiene implicaciones importantes en el mercado, pero exige el reconocimiento y la participación de un gran número de actuantes independientes que necesitan ser coordinados para lograr el potencial económico del sistema; y v) precios y mercados, fase actual que ha vinculado al concepto una amplia variedad de disciplinas, puesto que si no se comprenden completamente los precios y los mercados, se pueden convertir en barreras o limitantes, sin importar cuán bien se diseñe el sistema operativo. Esta fase apenas está comenzando y su punta de lanza son los mercados verdes.

\section{Metabolismo urbano}

El concepto de "metabolismo urbano" fue acuñado por el científico, inventor y profesor norteamericano, Abel Wolman, quien divulgó sus ideas en un artículo titulado "The metabolism of cities", publicado en 1965. Wolman planteó dos cosas: i) que las ciudades cuentan con una serie de necesidades metabólicas para sustentar a sus habitantes, como alimentos, combustible, ropa, bienes duraderos, materiales de construcción, energía eléctrica, entre otras muchas; y ii) que el ciclo metabólico solamente se completa cuando los residuos y desechos originados por las actividades diarias son retirados y eliminados sin generar peligros o incomodidades a los habitantes de las ciudades. Wolman cuestionó los métodos tradicionales empleados en las ciudades norteamericanas para eliminar residuos; señaló los altos índices de contaminación del aire y el agua, y centró su estudio en lo que denominó los tres problemas metabólicos más agudos: la provisión de un suministro adecuado de agua, la eliminación efectiva de las aguas residuales y el control de la contaminación del aire (Wolman, 1965). La propuesta de Wolman fue desestimada por la comunidad científica durante varias décadas, pero de manera reciente ha cobrado gran interés por parte de planificadores y otros estudiosos de los fenómenos urbanos que han rescatado y revalorado el metabolismo urbano. Actualmente se considera fundamental para el desarrollo de ciudades y comunidades sustentables. Kennedy, Pincetl y Bunje (2011) definen el metabolismo urbano como la suma total de los procesos técnicos y socioeconómicos que se producen en las ciudades, que se materializa en el crecimiento urbano, la producción de energía y la eliminación de todo tipo de residuos. Otros autores -aparte de los materiales, la energía y el agua- vinculan al metabolismo urbano variables socioeconómicas, además de vectores contaminantes, como los flujos de carbono (González, Donnelly, Jones, Chrysoulakis y Lopes, 2013). Otra línea de trabajo lo emplea como herramienta para acceder a sistemas de planificación urbano-regional más sostenibles, puesto que permite comprender la manera en que el desarrollo urbano impacta al ambiente local, regional y global (Conke y Ferreira, 2015). Por último, otros investigadores proponen un novísimo concepto, el "metabolismo urbano inteligente" que, gracias a las TIC, permite valorar los flujos urbanos de materia y energía en tiempo real (Shahrokni, Lazarevic y Brandt, 2015).

\section{Economía circular}

En 1970, Kneese, Ayres y D'Arge publicaron el libro Economics and the Environment: A Materials Balance Approach, en el que señalaron los efectos negativos de las externalidades industriales sobre el ambiente. Hacían énfasis en que, para el hombre primitivo, el mundo y sus recursos eran ilimitados, pero para las civilizaciones del siglo XX habían dejado de serlo. Plantearon el concepto de "equilibrio material" proponiendo que la gestión y el encausamiento del flujo de materiales correspondiera directamente a su valor económico. En 1990, el economista inglés David Pearce introdujo el concepto de economía sustentable, verde o ambiental, que controvertía las teorías económicas neoclásicas caracterizadas por su marcado enfoque antropocéntrico y, desde esa nueva perspectiva ambiental, definió cuatro funciones básicas que aporta el ambiente: i) valores de comodidad; ii) recursos naturales; iii) depósito o sumidero de residuos; iv) soporte de todas las formas de vida. Pearce publicó una serie de libros en colaboración con otros investigadores y sentó las bases de la economía circular, a la cual vinculó doce variables: producción, consumo, bienes de capital, utilidad, recursos naturales, reciclaje, residuos, recursos agotables, recursos reciclables, capacidad asimilativa, cosecha y rendimiento (Pearce, Markandya y Barbie, 1989; Pearce y Turner, 1990).

Recientemente, el campo de la economía circular se ha desarrollado de manera significativa. Preston (2012) esboza con claridad sus principales alcances: i) permite transformar la función de los recursos en la economía; ii) los residuos industriales se convierten en insumos para otras industrias; iii) al concluir su ciclo de vida, los productos pueden ser reparados, reutilizados o mejorados, en lugar de desechados; iv) en un mundo caracterizado por los altos y volátiles precios de los recursos, ofrece enormes oportunidades de negocios; v) si se acelera su implementación a través de políticas públicas, puede contribuir a la mitigación 
del cambio climático, la escasez de agua y otros desafíos globales; vi) puede contribuir a aliviar las preocupaciones concernientes al acceso a recursos e insumos. Por su parte, Ghisellini, Cialani y Ulgiati (2016) señalan que la transición hacia la economía circular acaba de empezar, y su marco interdisciplinario ofrece buenas perspectivas de mejoramiento (o cambio) para los actuales modelos de producción y consumo, que debido al impacto ambiental y la desigualdad social que generan, actualmente se consideran obsoletos. Para Genovese, Acquaye, Figueroa y Koh (2017), la economía circular debe crear "sistemas de producción autónomos en los que los materiales se utilizan una y otra vez" (p. 344). Estos autores, al igual que otros muchos, subrayan la estrecha relación entre economía circular y ecología industrial.

\section{Ecología industrial}

De acuerdo con Watanabe (1994), el término "ecología industrial" fue acuñado en 1971 por un grupo de investigación del Ministry of International Trade and Industry (MITI) del Japón. Desde entonces, define la política industrial de ese país a partir de los siguientes postulados: i) reconocer los límites del sistema (mundo), puesto que en su extremo está confinado a un área limitada: el planeta tierra; ii) reconocer las relaciones internas del sistema, pues cada una de las sustancias orgánicas e inorgánicas contribuye a la estabilidad de los ciclos naturales del planeta, a través de relaciones complejas; iii) reconocer las externalidades del sistema, pues ellas desempeñan un papel muy importante en el mantenimiento del equilibrio/desequilibrio del sistema; iv) reconocer las relaciones causa-efecto del sistema, especialmente las establecidas entre las actividades humanas y el ambiente, para mantener el equilibrio; v) reconocer las necesidades de autocontrol, buscando el equilibrio ideal entre las actividades humanas y los límites operativos del sistema.

Cabe subrayar que el concepto de ecología industrial se deriva de dos disciplinas: la ecología y la teoría de sistemas. Bajo los postulados de esas dos disciplinas busca estudiar el desarrollo y el comportamiento de los sistemas industriales desde el enfoque de los patrones de evolución de los sistemas naturales, lo que incluye: ciclo cerrado de materiales, principios evolutivos, resiliencia de los sistemas y retroalimentación dinámica (O'Rourke, Connelly y Koshland, 1996). Aunque son muchos los autores que han realizado aportes al concepto de ecología industrial, los objetivos que estableció John Ehrenfeld en 1994 continúan vigentes: i) mejorar las vías metabólicas para los procesos industriales y el uso de los materiales; ii) crear ecosistemas industriales de ciclo cerrado; iii) desmaterializar la producción industrial; iv) sistematizar los patrones de uso de energía; v) equilibrar los insumos y los productos industriales con la capacidad de los ecosistemas naturales; vi) alinear la política para ajustarse a la evolución del sistema industrial a largo plazo; vii) crear nuevas estructuras para acciones coordinadas, con vínculos comunicativos y de información (p. 16).

\section{Red de valor}

Según Gibson, Hanna, Defee y Chen (2014), la "red de valor" tuvo sus orígenes en la década de los ochenta, en los campos de la distribución y la comercialización, y, posteriormente, empezó a incluir otros eslabones de la cadena productiva. Desde la perspectiva organizacional, la red de valor surgió de integrar una amplia variedad de actividades relacionadas entre sí, pero que inicialmente estaban fragmentadas. En cuanto a definiciones, para Christopher (1992) se trata de una red de organizaciones que están involucradas a través de enlaces ascendentes y descendentes, en los diferentes procesos y actividades que producen valor en forma de productos $y$ servicios entregados al consumidor final. Por su parte, el Council of Supply Chain Management Professionals (2010) entiende el concepto como el intercambio de materiales e información en el proceso logístico, que se extiende desde la adquisición de materias primas hasta la entrega del producto terminado para el usuario final. Todos los vendedores, proveedores de servicios y los clientes son eslabones de la red de valor. De otro lado, Coyle, Langley, Novak y Gibson (2013) definen la red de valor como una serie de empresas integradas que deben compartir información y coordinar la ejecución física para asegurar un flujo de bienes, servicios, información y dinero de forma efectiva. Otros autores, como Stock y Boyer (2009) vinculan una multiplicidad de integrantes y canales al concepto de red de valor. Destacan los flujos de recursos hacia adelante y hacia atrás -"aguas abajo" y "aguas arriba" - y señalan que es gracias al funcionamiento y la dinámica del sistema, que involucra a todos los participantes de la(s) red(es), como se logran suplir los requerimientos del cliente. Por último, cabe subrayar que no existen redes de valor iguales, sus diferencias dependen de factores como su estructura, la industria y el sector al que pertenecen, el alcance geográfico de la actividad, la variedad de productos, los métodos de cumplimiento y los patrones de demanda.

\section{Logística inversa}

Una de las primeras descripciones de "logística inversa" la realizaron -desde la ingeniería industrial- Lambert y Stock en 1981: "Ir en la dirección equivocada en una calle de sentido único, porque la gran mayoría de envíos de productos fluyen en una dirección". Esta descripción se asemeja a la planteada por Murphy y Poist en 1989: "movimiento de bienes desde el consumidor hacia el productor, en un canal de distribución" (citado en Rogers y Tibben-Lembke, 2001, 
p. 129). En 1998 se acuñaron tres definiciones más: i) es el papel de la logística en el retorno de los productos, la reducción en la fuente, el reciclaje, la sustitución y la reutilización de materiales, la eliminación y renovación de desechos, la reparación y la remanufactura (Stock, 1998); ii) es el proceso por el cual las empresas pueden ser más eficientes desde el punto de vista ambiental a través del reciclaje, la reutilización y la reducción de la cantidad de materiales utilizados (Carter y Ellram, 1998); iii) la formulada por Rogers y Tibben-Lembke (1998):

\section{Es el proceso de planificación, implementación y control del flujo eficiente y rentable de materias primas, inventario en proceso, productos termi- nados e información relacionada, desde el punto de consumo hasta el punto de origen, con el pro- pósito de recuperar el valor asociado o definir su adecuada disposición.}

Durante el siglo XXI, el concepto ha evolucionado bastante. En 2003, el Council of Logistic Management la define como: "el proceso de mover bienes de su destino final a otro punto, con el propósito de capturar valor que de otra manera no estaría disponible para la disposición apropiada de los productos" (Don y Doldan, 2010, p. 220). Por su parte, Cure, Meza y Amaya (2006) la conciben como:

\section{El proceso de planificación, desarrollo y control eficiente del flujo de materiales, productos e información desde el último eslabón de la red de valor, hasta el lugar de origen, de manera que se satisfagan las necesidades del consumidor, recu- perando el residuo obtenido y gestionándolo de modo que sea posible su reintroducción en la cadena de suministro, obteniendo un valor agre- gado o consiguiendo una adecuada eliminación del mismo. (p. 186)}

Para Cabeza (2012), la logística inversa: "abarca el conjunto de actividades logísticas de recogida, desmontaje y desmembramiento de productos ya usados o sus componentes, así como de materiales de distinto tipo y naturaleza con el objeto de maximizar el aprovechamiento de su valor, en sentido amplio de su uso sostenible y, en último caso, su destrucción" (p. 26). Por último, Dyckhoff, Lackes y Reese (2013) consideran que la logística inversa comprende todas las actividades relacionadas con el manejo, el procesamiento, la reducción y la disposición de todos los residuos peligrosos y no peligrosos generados por la producción, además del embalaje y el uso de los productos, incluido el proceso de distribución inversa, y destacan su función ecológica, puesto que, gracias a ella, se pueden evitar innumerables impactos negativos sobre el ambiente.

\section{Psicología ambiental}

El término "psicología ambiental" fue acuñado en 1943 por el húngaro Egon Brunswik, quien lo usó por primera vez en un artículo publicado en la revista Psychological Review. De esa manera surgió un primer momento de esta disciplina, que estaba enfocado básicamente en las rela- ciones "ambiente-conducta", o sea, en los cambios conductuales generados por el ambiente. A mediados de la década de los setenta se consolidó un segundo momento orientado ahora, específicamente, a las conductas generadas por los espacios arquitectónicos y urbanos, y en su posterior desarrollo se le dio el nombre de "psicología de la arquitectura". Sin embargo, en esos dos momentos solo se estudiaban las relaciones ambiente-conducta. No fue sino hasta la década de los noventa cuando se desarrolló una psicología ambiental vinculada a la conservación del ambiente. A partir de entonces, se invirtió la relación precedente para empezar a estudiar las relaciones conducta-ambiente, es decir, los efectos ambientales generados por las conductas humanas. De manera que existen dos enfoques bien diferenciados de la psicología ambiental: i) el que analiza los efectos del ambiente -natural o construido- sobre la conducta humana; y ii) el que estudia los efectos de la conducta humana sobre el ambiente físico y natural.

En relación con el segundo enfoque se puede decir que existen dos clases de conductas fundamentales: i) la conducta responsable con el ambiente (o conducta sustentable), que busca conservarlo y protegerlo; y ii) la conducta irresponsable (o conducta insustentable), que genera destrucción y degradación ambiental. Cabe subrayar que el agente que causa los desequilibrios ambientales sobre el planeta es el ser humano, y debido a que las problemáticas ambientales que surgieron a partir de las décadas de los sesenta y setenta no lograron ser solucionadas por las ciencias naturales -que se pensaba eran las encargadas de estos asuntos-, la psicología ambiental empezó a jugar un papel decisivo en la búsqueda del equilibrio ambiental y de la sustentabilidad urbana (Baldi y García, 2006; Berroeta; 2007; Pol, 2006; Roth, 2000). Para Moser (2003), la psicología ambiental tiene por objeto identificar los procesos que regulan la relación del individuo con el ambiente, evidenciando el imaginario que el individuo tiene del ambiente, y los comportamientos que lo acompañan. Moser define la psicología ambiental como: "el estudio de las interrelaciones entre el individuo y su ambiente físico y social, dentro de sus dimensiones espaciales y temporales" (p. 14).

\section{Ecodiseño}

Según Ryan (2003, 2004), el ecodiseño -también conocido como diseño para el medio ambiente o diseño verde- surgió en los Países Bajos a principios de la década de los noventa, y los primeros experimentos para aplicar sus principios a gran escala fueron financiados, en esa misma década, por los gobiernos de Australia y los Países Bajos. Señala Ryan el enorme número de guías para el ecodiseño que pronto emergieron desde los campos del diseño y la ingeniería industrial y, además, que para 2003 ya existían 26 mil sitios de internet dedicados a ese tipo de 
diseño amigable con el ambiente. En cuanto a su definición, Glavic y Lukman (2007) lo conciben como "un proceso de desarrollo de producto que tiene en cuenta su ciclo de vida completo, y considera aspectos ambientales en todas las etapas del proceso, buscando productos que generen el impacto ambiental más bajo posible a lo largo del ciclo de vida" (p. 1875). Mencionan, además, que el ecodiseño busca la reducción de materiales de entrada, la minimización de externalidades negativas a la salida, así como la reducción de los riesgos para la salud humana; y que se relaciona estrechamente con la evaluación del ciclo de vida, la ingeniería ambiental o verde, y los procesos de reutilización, reciclaje y remanufacturación. Por su parte, Balboa y Domínguez (2014) lo vinculan con la economía circular.

Desde el campo de la arquitectura, a finales de la década de los noventa, el arquitecto malayo Ken Yeang (1999) publicó el libro, Proyectar con la naturaleza: bases ecológicas para el proyecto arquitectónico, en el cual abordó todos los principios que hasta aquí se han mencionado a cerca del ecodiseño; con esa publicación logró renovar las bases del diseño arquitectónico, el diseño del paisaje y la planificación urbano-regional. Del mismo autor -en colaboración con Lillian Woo- es el Dictionary of Ecodesign: An Illustrated Reference, un libro dirigido a profesionales pertenecientes a una amplia gama de disciplinas, puesto que el ecodiseño es totalmente incluyente. Presentamos la entrada correspondiente a ecodiseño del diccionario de Yeang y Woo (2010):

También conocido como diseño sustentable, diseño ecológico del ambiente construido, arquitectura verde y diseño verde. Es el manejo del uso de los procesos de un ecosistema y recursos no renovables a través del eco-mimetismo. Sus principales objetivos son la integración física y mecánica de las formas e infraestructuras construidas con las características y los procesos del ecosistema de un sitio determinado; la prevención del agotamiento de los recursos de energía, agua y materias primas; la prevención de la degradación ambiental causada por las instalaciones y su ciclo de vida; y la creación de una bio-integración entre el entorno construido y el entorno natural. Incluye cualquier forma de diseño que minimice los impactos destructivos del medio ambiente mediante la integración física, sistemática y temporal con los procesos vivos del entorno natural. (p. 79)

\section{Análisis comparativo}

La síntesis del análisis comparativo de los conceptos estudiados se presenta en la Tabla 2.

Del análisis comparativo surgieron once axiomas que sirven de fundamento a la propuesta: Bucle multidisciplinar para la sustentabilidad urbana.

1. El concepto de ciclo cerrado -que surgió en el siglo XVIII-, fue retomado como marco teórico por al menos seis propuestas conceptuales: i) metabolismo urbano; ii) economía circular; iii) ecología industrial; iv) redes de valor; v) logística inversa; y vi) eco-diseño.
2. Todos los conceptos estudiados coinciden en dos cosas: i) buscan los mismos objetivos; y ii) todos hacen parte de procesos humanos, industriales y urbanos.

3. El mundo es un sistema limitado y sus recursos son finitos. Es prioritario reducir la explotación de los recursos recuperando los productos usados, sus materiales o sus partes, para reintroducirlos en nuevos ciclos de producción, en lugar de desecharlos ${ }^{9}$.

4. Es fundamental establecer mercados verdes, donde los productos que han cumplido su ciclo de vida puedan ser revalorados económicamente y comercializados.

5. Las externalidades generadas por el metabolismo urbano e industrial afectan la naturaleza: es esencial reducirlas. Los residuos que inevitablemente sean generados, deben reutilizarse o reintroducirse en los procesos industriales y urbanos de manera inteligente ${ }^{10}$.

6. Es fundamental recuperar la energía embebida o incorporada ${ }^{11}$ en los materiales que sirven de insumo a la industria y a la ciudad, puesto que la generación de esa energía no solo requiere de recursos naturales, sino que genera gran cantidad de externalidades.

7. En todos los procesos industriales y urbanos se debe buscar la integración de las organizaciones y las personas involucradas, para que compartan información, establezcan el intercambio de materiales y fomenten la cooperación; en lugar de mantenerlas aisladas, desintegradas y compitiendo entre sí.

8. Todo producto tiene un valor económico, ambiental y humano -aun cuando haya cumplido su ciclo de vida útil-, puesto que en él se han invertido recursos naturales y recursos económicos, energía y agua, procesos industriales y procesos urbanos, y su producción ha generado externalidades. En consecuencia, debe recuperarse.

9. Para mantener el equilibrio ambiental es necesario replantear la relación seres humanos-naturaleza, porque los seres humanos generan el desequilibrio.

10. Es esencial modificar las conductas humanas -individuales y colectivas- en relación con el ambiente, para que sean sustentables.

9 Este objetivo se fomenta ligando el valor económico real al flujo de materiales que recorren la ciudad y la industria -incluyendo los materiales que hacen parte de productos que han concluido su ciclo de vida-. Así, se puede aprovechar e valor comercial de los materiales y rescatar la energía embebida o incorporada en ellos.

10 Por ejemplo, estableciendo parques industriales donde los residuos de una industria sirvan de insumo para otra, tal como sucede en la naturaleza. O reutilizando los materiales o las partes de algunos productos, objetivo que se puede realizar de manera muy simple y eficiente con los materiales de construcción.

11 La energía embebida o incorporada es toda la energía que se empleó para la fabricación de un material, desde la extracción de materias primas, pasando por los procesos industriales, incluidos todos los requerimientos de transporte $y$ distribución involucrados. 


\begin{tabular}{|c|c|c|c|c|c|c|c|}
\hline \multicolumn{8}{|c|}{ Conceptos teóricos que fortalecen la sustentabilidad urbana } \\
\hline $\begin{array}{c}\text { Ciclo cerrado } \\
1735\end{array}$ & $\begin{array}{c}\text { Metabolismo } \\
\text { urbano } \\
1965\end{array}$ & $\begin{array}{c}\text { Economía } \\
\text { circular } 1970\end{array}$ & $\begin{array}{c}\text { Ecología } \\
\text { industrial } \\
1971\end{array}$ & $\begin{array}{c}\text { Red de valor } \\
1980\end{array}$ & $\begin{array}{c}\text { Logística } \\
\text { inversa } 1981\end{array}$ & $\begin{array}{c}\text { Psicología } \\
\text { ambiental } \\
1990\end{array}$ & $\begin{array}{c}\text { Ecodiseño } \\
1990\end{array}$ \\
\hline $\begin{array}{c}\text { Movimiento } \\
\text { que inicia en un } \\
\text { punto, recorre un } \\
\text { sistema y retorna } \\
\text { al punto de } \\
\text { partida. Bucle }\end{array}$ & $\begin{array}{c}\text { La ciudad } \\
\text { cumple un ciclo } \\
\text { metabólico que } \\
\text { se cierra cuando } \\
\text { los residuos } \\
\text { desaparecen sin } \\
\text { causar daño }\end{array}$ & $\begin{array}{l}\text { Los recursos } \\
\text { naturales son } \\
\text { finitos. Las } \\
\text { externalidades } \\
\text { destruyen el } \\
\text { ambiente. El } \\
\text { equilibrio material } \\
\text { se logra ligando el } \\
\text { flujo de materiales } \\
\text { a valores } \\
\text { económicos }\end{array}$ & $\begin{array}{c}\text { El mundo es un } \\
\text { sistema limitado. } \\
\text { Las externalidades } \\
\text { afectan el } \\
\text { sistema. Se debe } \\
\text { establecer un } \\
\text { equilibrio en las } \\
\text { relaciones causa- } \\
\text { efecto entre el } \\
\text { ser humano y la } \\
\text { naturaleza }\end{array}$ & $\begin{array}{c}\text { Se deben integrar } \\
\text { actividades } \\
\text { relacionadas } \\
\text { de los procesos } \\
\text { de producción } \\
\text { que estaban } \\
\text { fragmentadas. } \\
\text { Crear el ciclo y } \\
\text { cerrar el ciclo }\end{array}$ & $\begin{array}{c}\text { Movimiento de } \\
\text { bienes desde el } \\
\text { consumidor hacia } \\
\text { el productor. } \\
\text { Bienes que han } \\
\text { cumplido su ciclo, } \\
\text { en reversa }\end{array}$ & $\begin{array}{l}\text { Estudia los efectos } \\
\text { ambientales } \\
\text { generados por } \\
\text { las conductas } \\
\text { humanas. } \\
\text { Establece dos } \\
\text { conductas: } \\
\text { sustentable e } \\
\text { insustentable }\end{array}$ & $\begin{array}{c}\text { Tiene en cuenta } \\
\text { el ciclo de } \\
\text { vida completo } \\
\text { del producto, } \\
\text { y considera } \\
\text { aspectos } \\
\text { ambientales } \\
\text { en todas las } \\
\text { etapas del } \\
\text { proceso y vida } \\
\text { útil }\end{array}$ \\
\hline $\begin{array}{c}\text { Recupera } \\
\text { productos usados. } \\
\text { Remanufactura. } \\
\text { Valora la logística } \\
\text { inversa }\end{array}$ & $\begin{array}{l}\text { Suma total de } \\
\text { procesos técnicos, } \\
\text { económicos y } \\
\text { sociales urbanos, } \\
\text { que se materializa } \\
\text { en: crecimiento } \\
\text { urbano, } \\
\text { producción } \\
\text { de energía y } \\
\text { eliminación de } \\
\text { todo tipo de } \\
\text { residuos }\end{array}$ & $\begin{array}{c}\text { Economía } \\
\text { sustentable } \\
\text { opuesta al } \\
\text { enfoque } \\
\text { antropocéntrico y } \\
\text { explotador de la } \\
\text { visión neoclásica. } \\
\text { Identifica cuatro } \\
\text { funciones del } \\
\text { ambiente: } \\
\text { comodidad, } \\
\text { recursos, } \\
\text { sumidero, soporte } \\
\text { de la vida }\end{array}$ & $\begin{array}{c}\text { Los sistemas } \\
\text { industriales imitan } \\
\text { a los sistemas } \\
\text { naturales. } \\
\text { Ciclo cerrado } \\
\text { de materiales. } \\
\text { Resiliencia. } \\
\text { Mejorar vías } \\
\text { metabólicas } \\
\text { en procesos } \\
\text { industriales y uso } \\
\text { de materiales. } \\
\text { Ecosistemas } \\
\text { industriales de } \\
\text { ciclo cerrado. } \\
\text { Desmaterializa } \\
\text { la producción } \\
\text { industrial }\end{array}$ & $\begin{array}{l}\text { Intercambio } \\
\text { de materiales } \\
\text { e información } \\
\text { en el proceso } \\
\text { productivo } \\
\text { de bienes y } \\
\text { servicios. Red de } \\
\text { organizaciones } \\
\text { involucradas a } \\
\text { través de enlaces } \\
\text { ascendentes y } \\
\text { descendentes. } \\
\text { Aguas arriba y } \\
\text { aguas abajo }\end{array}$ & $\begin{array}{c}\text { Retornar } \\
\text { productos. } \\
\text { Reducir necesidad } \\
\text { de materiales. } \\
\text { Reciclar. } \\
\text { Renovar desechos. } \\
\text { Reparar. } \\
\text { Remanufacturar. } \\
\text { Reintroducir } \\
\text { residuos en } \\
\text { la cadena de } \\
\text { producción. } \\
\text { Aprovechar } \\
\text { el valor de } \\
\text { productos } \\
\text { desechados }\end{array}$ & $\begin{array}{c}\text { Estudia la } \\
\text { interrelación entre } \\
\text { el individuo y su } \\
\text { ambiente físico y } \\
\text { social, dentro de } \\
\text { sus dimensiones } \\
\text { espaciales y } \\
\text { temporales }\end{array}$ & $\begin{array}{c}\text { Integración física } \\
\text { y mecánica } \\
\text { de las formas } \\
\text { y estructuras } \\
\text { construidas con } \\
\text { las características } \\
\text { y los procesos } \\
\text { del ecosistema } \\
\text { de un sitio } \\
\text { determinado }\end{array}$ \\
\hline
\end{tabular}

11. El diseño de un producto, un objeto arquitectónico o una pieza urbana debe dirigirse bajo los postulados del ecodiseño, que no solo contemplan el "ciclo cerrado", sino que armonizan la relación entre el mundo natural y el construido, desde su origen.

\section{Bucle multidisciplinar para la sustentabilidad urbana}

Los procesos urbanos, económicos, industriales y humanos que involucran las ciudades para su normal funcionamiento son responsables de la extracción de enormes cantidades de energía, materiales y agua que, al ser procesados al interior de las urbes, generan gran cantidad de externalidades. Con el fin de reducir la explotación de los recursos naturales y la degradación de los ecosistemas y la biodiversidad, durante los últimos trescientos años han surgido -desde varias disciplinas y de manera aislada- una serie de conceptos que buscan renovar el equilibrio entre la naturaleza y la especie humana. Infortunadamente, esos conceptos teóricos, tan valiosos para el equilibrio ambiental, se han mantenido en distintas parcelas disciplinares, aislados, separados, encapsulados, encriptados, cerrados sobre sí mismos, o mejor: enclaustrados dentro de las murallas de sus propias disciplinas. Al pun- to que, normalmente, solo se tiene acceso a cada uno de ellos desde su disciplina correspondiente. Infortunadamente, aunque comparten un mismo objetivo -que es la sustentabilidad urbana y global-, no se relacionan ni articulan entre sí.

Lo anterior se explica porque las diversas perspectivas disciplinares -que solo captan una parte fragmentada de la realidad-, deben hacerlo así para lograr estudiarla de manera detallada y específica. Son campos disciplinares creados y compartimentados artificialmente, en los que predomina la tendencia a observar un objeto en forma fragmentada (Baldi y García, 2006).

En consecuencia, urge que los conceptos que fortalecen la sustentabilidad urbana -que se presentan en este artículo-, aunque históricamente surgieron de distintas disciplinas, ahora se integren, se estructuren y se articulen, para que logren actuar como un sistema multidisciplinar unificado y compacto. Así, sus efectos serán más sólidos, eficaces y eficientes. Para unificarlos e integrarlos proponemos un modelo dinámico, el Bucle multidisciplinar para la sustentabilidad urbana, en el cual ocho conceptos para la sustentabilidad urbana que surgieron desde diversas disciplinas, y que por décadas se mantuvieron aislados, se unifiquen trazando un bucle en torno a la ciudad, generen vasos
(A) Tabla 2. Conceptos teóricos que fortalecen la sustentabilidad urbana, tabla comparativa

Fuente: elaboración propia a partir de diversas fuentes, 2018. 
$\rightarrow$ Figura 7. Bucle multidisciplinar para la sustentabilidad urbana Fuente: elaboración propia, 2018

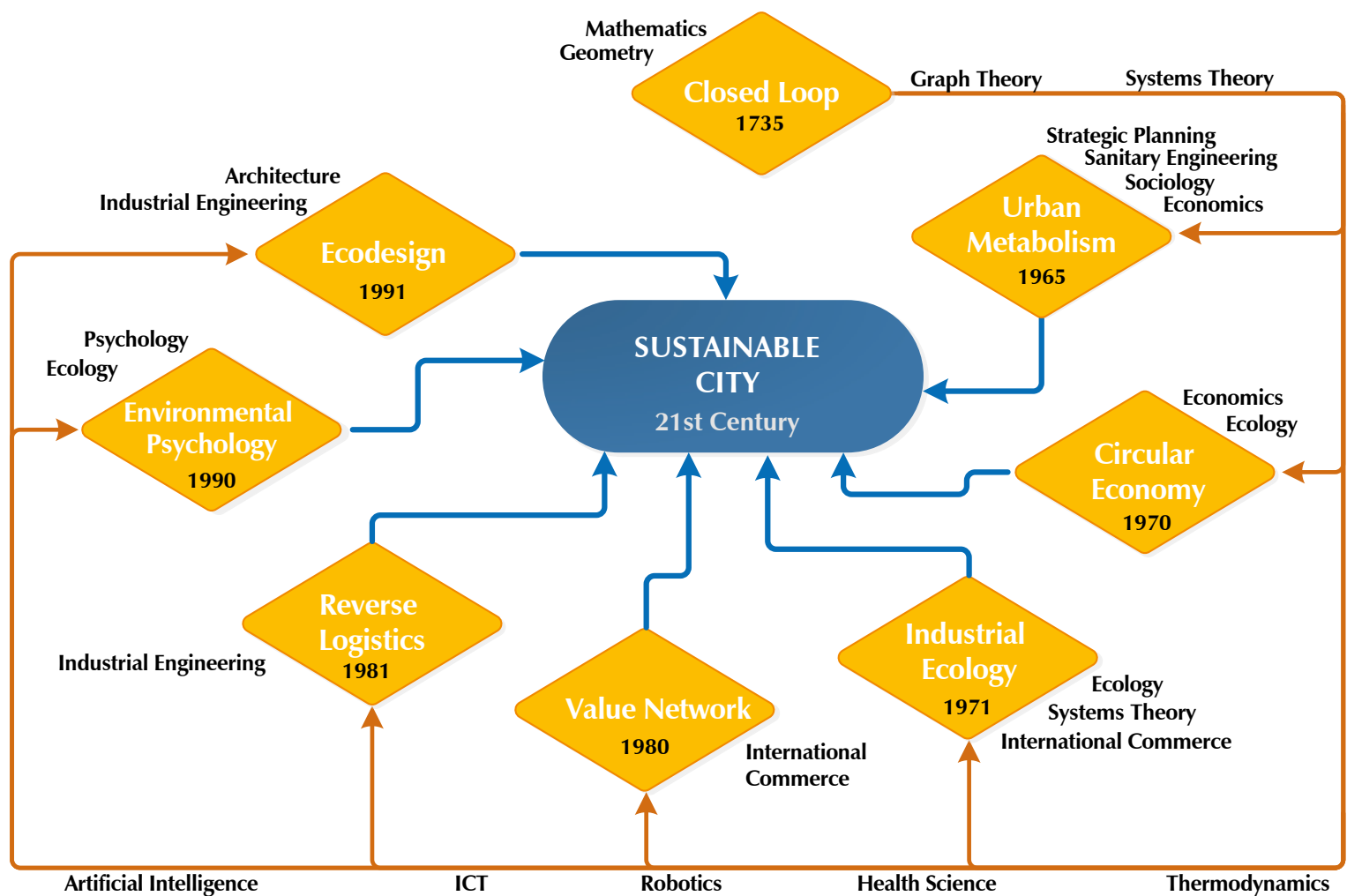

comunicantes entre las diversas disciplinas que involucran, $y$, al trabajar mancomunadamente, fortalezcan de manera significativa la sustentabilidad de las ciudades (Figura 7).

Es prioritario que cada uno de los conceptos -y las disciplinas- que integran el Bucle multidisciplinar para la sustentabilidad urbana empiece a interactuar, aprehender y dialogar con los otros, aunque pertenezcan o hayan surgido de disciplinas distintas, pues, al fin y al cabo y de hecho, todos se integran en una misma realidad: la ciudad contemporánea.

\section{Discusión}

Actualmente, la literatura relativa a la sustentabilidad urbana tiende, en su mayoría, a enlistar una serie de buenas intenciones, agrupadas en conjuntos o no; por ejemplo: "Vibrante, armoniosas e inclusivas comunidades, en el conjunto social y cultural" (Office of the Deputy Prime Minister, 2004); o, "mantener la calidad ambiental y la capacidad de carga, apoyar el desarrollo y la gestión socioeconómica, además de brindar suficientes servicios y medios de vida a todos los habitantes actuales y futuros" (Tang y Lee, 2016); o, "eficiencia energética en edificios públicos, zonas de tráfico limitado y gestión de tierras y recursos" (Gargiulo et al., 2017); o, "reducir la desigualdad económica en los barrios" (Sampson, 2017); o "movilidad urbana sostenible" (Hodson, Geels y McMeekin, 2017). Pero, icómo se materializan esas buenas intenciones?

Otras iniciativas se enfocan en un único factor generador de insustentabilidad, como el Transit Oriented Development (TOD) ${ }^{12}$ que se concen-

12 Ver Transit Oriented Development Institute, en http://www. tod.org tra en la movilidad y genera soluciones parciales. Pero, ¿qué pasa con los demás factores generadores de desequilibrio?

Un tercer grupo de propuestas establece políticas y documentos, como por ejemplo, la Política de Gestión Ambiental Urbana (MAVDT, 2008), directriz colombiana que apunta a resolver la "falta de articulación y coordinación que tradicionalmente se han presentado entre las autoridades ambientales de los Grandes Centros Urbanos" (p. 27), además de definir lo que es una ciudad sostenible que, según el documento, se caracteriza porque: "Conoce la base natural que la soporta y desarrolla estrategias de conservación [...] Implementa planes de gestión integral del riesgo [...] Contribuye al mejoramiento del hábitat urbano, asegurando la sostenibilidad ambiental" (p. 27). Pero, ¿no es acaso este discurso otro listado de buenas intenciones que nadie sabe cómo trasladar a la práctica?

Por el contrario, el Bucle multidisciplinar para la sustentabilidad urbana descansa sobre ocho conceptos que fortalecen dicha sustentabilidad: ciclo cerrado, metabolismo urbano, economía circular, ecología industrial, red de valor, logística inversa, psicología ambiental y ecodiseño (Figura 7). Conceptos que ya existen y que, además, ya se han puesto en práctica con bastante éxito en distintas regiones y países. Pero su puesta en escena se ha caracterizado por la individualidad. De manera que actúan desarticulados, disgregados y desacoplados, en forma fragmentaria y con resultados positivos, pero igualmente fraccionados. En consecuencia, dichos conceptos no actúan en un contexto -la ciudad-, ni lo hacen como componentes de un sistema articulado e integrado. Por el contrario, actúan como ruedas sueltas. Lo que logran lo hacen de manera ais- 
lada y parcial. Es, precisamente, para organizar estas teorías en un conjunto ${ }^{13}$ o sistema complejo que surge la propuesta del Bucle interdisciplinar para la sustentabilidad urbana, el cual se estructura bajo el concepto del desarrollo sustentable, y podrá ser aplicado, cuando se diseñe como herramienta, a ciudades, municipios, distritos, poblados o aldeas.

\section{Conclusiones}

Las ciudades del siglo XXI están pasando por una época de grandes cambios. Uno de los más trascendentes y necesarios consiste en que los profesionales e investigadores de una disciplina, sin importar cuál sea, incursionen en otros campos de conocimiento, porque esa exploración les permite crear vasos comunicantes y redes interdisciplinares que: i) estimulan y fertilizan la creatividad humana (Florida, 2009); ii) facilitan la creación de nuevas formas de hacer las cosas -para hacerlas de manera sustentable-; iii) con-

13 “En el planteamiento sistémico las propiedades de las partes solo se pueden comprender desde la organización del conjunto" (Capra, 1998, p. 7). tribuyen con el desplome de los viejos paradigmas urbanos que no solo permanecen enquistados en el núcleo de la sociedad, sino en las percepciones y conductas de los ciudadanos. Paradigmas obsoletos e insustentables que impiden alcanzar un bienestar humano verdaderamente equitativo y ambientalmente sano y que, por tanto, urge desmantelar. Porque, mientras persistan, continuarán destruyendo la fuente de la energía, los materiales y el agua que tanto requieren la humanidad y las ciudades para sobrevivir, es decir, la naturaleza.

Por tanto, es prioritario que los profesionales que de alguna manera inciden en las dinámicas urbanas de las ciudades contemporáneas -sean planificadores, arquitectos, urbanistas, ingenieros industriales, ingenieros civiles, ingenieros viales, ingenieros hidráulicos, economistas, sociólogos, psicólogos, matemáticos, entre otros-, conozcan y utilicen como una herramienta para su trabajo el Bucle multidisciplinar para la sustentabilidad urbana; analicen y valoren sus diversos y variados componentes, y al momento de planificar actividades nuevas -que puedan impactar las dinámicas y el ambiente de la vida urbana- los tengan en cuenta.

\section{Referencias}

American Council for an Energy-Efficient Economy (ACEEE) (2017). Community-wide energy consumption by city and year. Washington, D. C.: American Council for an EnergyEfficient Economy-ACEEE. Recuperado de https://database.aceee.org/sites/default/files/ docs/local-energy-data.pdf

Alfonso, W. H. y Pardo, C. I. (2014). Urban material flow analysis: An approach for Bogotá, Colombia. Ecological indicators, (42), 32-42. https:// doi.org/10.1016/j.ecolind.2013.10.035

Balboa C. C. y Domínguez Somonte, M. (2014). Economía circular como marco para el ecodiseño: el modelo ECO-3. Informador técnico, 78(1), 82-90. https://doi.org/10.23850/22565035.71

Baldi López, G. y García Quiroga, E. (2006). Una aproximación a la psicología ambiental. Fundamentos en humanidades, VII (1314), 157-168.

Banco Mundial (2017). Población urbana (\% del total). Recuperado de https://datos.bancomundial.org/indicador/SP.URB.TOTL.IN.ZS

Berroeta, H. (2007). Espacio público: notas para la articulación de una psicología ambiental comunitaria. En J. Alfaro y $\mathrm{H}$. Berroeta (eds.). Trayectoria de la psicología comunitaria en Chile (pp. 259-285). Valparaíso: Editorial Universidad de Valparaíso.

Bertalanffy, L. (1993). Teoría general de los sistemas. México: Fondo de Cultura Económica. Recuperado de https://cienciasyparadigmas.files.wordpress.com/2012/06/ teoria-general-de-los-sistemas-_fundamentos-desarrollo-aplicacionésludwig-von-bertalanffy.pdf
Brunswik, E. (1943). Organismic achievement and environmental probability. Psychological Review, 50(3), 255. http://dx.doi. org/10.1037/h0060889

Cabeza, D. (2012). Logística inversa en la gestión de la cadena de suministro. Barcelona: Marge books.

Capra, F. (1998). La trama de la vida: una nueva perspectiva de los sistemas vivos. Barcelona: Anagrama.

Carter, C. R. y Ellram, L. M. (1998). Reverse logistics: A review of the literature and framework for future investigation. Journal of Business Logistics, 19(1), 85-102.

Christopher, M. (1992). Logistics and Supply Chain Management. London: Pitman Publishing.

City of New York (2011). PlaNYC a greener, greater New York. New York: City of New York.

Conke, L. S. y Ferreira, T. L. (2015). Urban metabolism: Measuring the city's contribution to sustainable development. Environmental Pollution, (202), 146-152. https:// doi.org/10.1016/j.envpol.2015.03.027

Council of Supply Chain Management Professionals (2010). Supply Chain Management Terms and Glossary. Recuperado de http:// www.iwla.com/assets/1/24/2010_Glossary_ of Terms 10.7.11.pdf

Coyle, J. J., Langley, C. J., Novack, R. A. y Gibson, B. J. (2013). Supply Chain Management: $A$ Logistics Perspective. Mason: South-Western Cengage Learning.

Cure, L., Meza, J. C. y Amaya, R. (2006). Logística Inversa: una herramienta de apoyo a la competitividad de las organizaciones. Ingeniería y desarrollo, (20) 184-202. Recuperado de http://hdl.handle.net/10584/4142

Don, D. y Doldan, J. (2010). La logística inversa como herramienta de la gestión ambiental. Ciencia y Tecnología, (10), 217-224. Recuperado de http://hdl.handle.net/10226/1379

Dyckhoff, H., Lackes, R. y Reese, J. (eds.) (2013). Supply chain management and reverse logistics. Berlin: Springer.

Ehrenfeld, J. R. (2009). Understanding of complexity expands the reach of industrial ecology. Journal of Industrial Ecology, 13(2), 165-167. https://doi.org/10.1111/j.15309290.2009.00118.x

Ehrenfeld, John (1994). Understanding of complexity expands the reach of industrial ecology. Journal of Industrial Ecology, 13(2), 165-167. https://doi.org/10.1111/j.15309290.2009.00118.x

Fernández Durán, R. (2011, mayo). Un planeta de metrópolis (en crisis). Explosión urbana y del transporte motorizado, gracias al petróleo. Habitat y sociedad, 2. 205-239. http://dx.doi.org/10.12795/HabitatySociedad.2011.i2.12

Florida, R. (2009). La clase creativa: .a transformación de la cultura del trabajo y el ocio en el siglo XXI. Barcelona: Paidos.

Franke, B., Busch, M. y Zeitz, C. (s. f.). Urban material and energy flows and their potential for synergetic use. Rapid Planning. Recuperado de https://www.ifeu.de/ wp-content/uploads/IFEU-Urban-Materialand-Energy-Flows-Final-Draft-1.0.pdf 
Gargiulo, M., Chiodi, A., De Miglio, R., Simoes, S., Long, G., Pollard, M. et al. (2017). An integrated planning framework for the development of sustainable and resilient cities-the case of the InSMART project. Procedia Engineering, 198, 444-453.

Genovese, A., Acquaye, A. A., Figueroa, A. y Koh, S. L. (2017). Sustainable supply chain management and the transition towards a circular economy: Evidence and some applications. Omega, (66), 344-357. https:// doi.org/10.1016/j.omega.2015.05.015

Ghisellini, P., Cialani, C. y Ulgiati, S. (2016). A review on circular economy: The expected transition to a balanced interplay of environmental and economic systems. Journal of Cleaner Production, (114), 11-32. https:// doi.org/10.1016/j.jclepro.2015.09.007

Gibson, B. J., Hanna, J. B., Defee, C. C. y Chen, H. (2013). The Definitive Guide to Integrated Supply Chain Management: Optimize the Interaction Between Supply Chain Pro cesses, Tools, and Technologies. New York: Pearson Education.

Glavic, P. y Lukman, R. (2007). Review of sustainability terms and their definitions. Journal of Cleaner Production, 15(18), 1875-1885. https:// doi.org/10.1016/j.jclepro.2006.12.006

Gobierno de la Ciudad de Buenos Aires (2009). Informe anual ambiental 2009. Buenos Aires: Ministerio de ambiente y espacio público. Recuperado de http://estatico.buenosaires. gov.ar/areas/med_ambiente/apra/educ com/archivos/informe2009.pdf

Gobierno de la Ciudad de México (2012). Registro de emisiones de gases de efecto invernadero del distrito federal. México D. F.: Secretaría del Medio Ambiente y Recursos Naturales. Recuperado de https://www.gob.mx/semarnat/acciones-y-programas/registro-nacional-de-emisiones-rene

Gobierno de la Ciudad de México (2015). Inventario de residuos sólidos. México D. F. Gobierno de la Ciudad de México. Recuperado de https://docplayer.es/39573579-Inventario-de-residuos-solidos-ciudad-de-mexico. html

González, A., Donnelly, A., Jones, M., Chrysoulakis, N. y Lopes, M. (2013). A decision-support system for sustainable urban metabolism in Europe. Environmental Impact Assessment Review, (38), 109-119. https://doi. org/10.1016/j.eiar.2012.06.007

González, G. L. (2010). Residuos sólidos urbanos Argentina: Tratamiento y disposición final, situación actual y alternativas futuras. Buenos Aires: Cámara Argentina de la Construcción.

Guide Jr, V. D. R. y van Wassenhove, L. N. (2009). OR FORUM-The evolution of closed-loop supply chainresearch. OperationsResearch, 57(1), 10-18. https://doi.org/10.1287/opre.1080.0628

Hodson, M. Geels, W. G. y McMeekin, A. (2017) Reconfiguring urban sustainability transitions, analysing multiplicity. Sustainability, 9(2), 299-319. http://www.mdpi.com/20711050/9/2/299

Jiménez, M. y Santana, F. (2017). Water distribution system of Bogotá City and Its surrounding area, Empresa de Acueducto y Alcantarillado de Bogotá-EAB ESP. Procedia Engineering, (186), 643-653. https://doi. org/10.1016/j.proeng.2017.03.281

Kennedy, C. A., Stewart, I., Facchini, A., Cersosimo, I., Mele, R., Chen, B. et al. (2015). Energy and material flows of megacities. Proceedings of the National Academy of Sciences, 112(19), 5985-5990. https://doi. org/10.1073/pnas.1504315112

Kennedy, C., Pincetl, S. y Bunje, P. (2011). The study of urban metabolism and its applications to urban planning and design. Environ- mental pollution, 159(8), 1965-1973. https:// doi.org/10.1016/j.envpol.2010.10.022

Kneese, A. V., Ayres, R. V. y D'Arge, R. C. (1970). Economics and the environment: A materials balance approach. Baltimore: John Hopkins University Press.

Lambert, D. M. y Stock, J. R. (1981). Strategic Planning for Physical Distribution. Journal of Business Logistics, 3(2), 26-46.

Ministerio de Ambiente, Vivienda y DesarroIlo Territorial (MAVDT) (2008). Política de Gestión Ambiental Urbana. Bogotá, D.C.: MAVDT.

Moser, G. (2003). La psicología ambiental en el siglo 21: el desafío del desarrollo sustentable. Revista de psicología, 12(2), 11-17. https:// doi.org/10.5354/0719-0581.2012.17386

Murphy, P. R. y Poist, R. P. (1989). Management of logistical retromovements: An empirical analysis of literature suggestions. Transportation Research Forum, 29(1), 177-84. Recuperado de: https://trid.trb.org/view/290499

Musterd, S. y Ostendorf, W. (eds.). (2013). Urban segregation and the welfare state: Inequality and exclusion in western cities. New York: Routledge.

Núñez, J., Alfonso, M., Bueno, S., Diánez, M y Olivenza, E. (2004). Siete puentes, un camino: Königsberg. Suma, (45), 69-78. Recuperado de http://revistasuma.es/revis tas/45-febrero-2004/siete-puentes-un-camino-konigsberg.html

Office of the Deputy Prime Minister (2004). Skills for sustainable communities. London: Office of the Deputy Prime Minister.

O'Rourke, D., Connelly, L. y Koshland, C. P. (1996). Industrial ecology: A critical review. International Journal of Environment and Pollution, 6(2-3), 89-112. Recuperado de http://web.mit.edu/dorourke/www/PDF/ IE.pdf

Pearce, D. y Turner, R. K. (1990). Economics of natural resources and the environment. London: Harvester Wheatsheaf.

Pearce, D., Markandya, A. y Barbier, E. (1989). Blueprint for a Green Economy. London: Earthscan Publications.

Pol, E. (2006). Blueprints for a history of environmental psychology (I): From first birth to American transition. Medio ambiente $y$ comportamiento humano, 7(2), 95-113. Recuperado de https://mach.webs.ull.es/ PDFS/Vol7 2/Vol7 2 e.pdf

Preston, F. (2012). A Global Redesign?: Shaping the Circular Economy. London: Chatham House.

Rogers, D. y Tibben-Lembke, R. S. (1998). Going Backwards: Reverse Logistics Trends and Practices. Reno: Reverse Logistics Executive Council. Recuperado de http://www. abrelpe.org.br/imagens_intranet/files/logistica_reversa.pdf

Rogers, D. S. y Tibben-Lembke, R. S. (2001). An examination of reverse logistics practices. Journal of Business Logistics, 22(2), 129-148. https://doi.org/10.1002/j.2158-1592.2001. tb00007.x

Roth, E. (2000). Psicología ambiental: interfase entre conducta y naturaleza. Revista Ciencia y Cultura, (8), 63-78. Recuperado de http:// www.scielo.org.bo/scielo.php?script=sci arttext\&pid=S2077-33232000000200007\&ln$\mathrm{g}=\mathrm{es} \& \operatorname{lng}=\mathrm{es}$

Rucks-Ahidiana, Z. y Harding, D. J. (2015) Urban poverty. En G. Ritzer (ed.). The Black well Encyclopedia of Sociology. Hoboken: Wiley-Blackwell Publishing.
Ryan, C. (2003). Learning from a decade (or so) of eco-design experience, Part I. Journal of Industrial Ecology, 7(2), 10-12. https://doi. org/10.1162/108819803322564316

Ryan, C. (2004). Learning from a decade (or so) of eco-design experience, Part II: Advancing the practice of product eco-design. Journal of Industrial Ecology, 8(4), 3-5. https://doi. org/10.1162/1088198043630540

Sampson, R. J. (2017). Urban sustainability in an age of enduring inequalities: Advancing theory and ecometrics for the 21st-century city. PNAS, 114(34), 8957-8962. https://doi. org/10.1073/pnas.1614433114

Schaffartzik, A., Mayer, A., Gingrich, S., Eisenmenger, N., Loy, C. y Krausmann, F. (2014). The global metabolic transition: Regional patterns and trends of global material flows, 1950-2010. Global Environmental Change, (26), 87-97. https://doi.org/10.1016/j.gloenvcha.2014.03.013

Shahrokni, H., Lazarevic, D. y Brandt, N. (2015) Smart urban metabolism: Towards a realtime understanding of the energy and material flows of a city and its citizens. Journal of Urban Technology, 22(1), 65-86. https://doi. org/10.1080/10630732.2014.954899

Stock, J. y Boyer, S. (2009). Developing a consensus definition of supply chain management: A qualitative study. International Journal of Physical Distribution \& Logistics Management, 39(8), 690-711. https://doi. org/10.1108/09600030910996323

Stock, J. R. (1998). Development and Implementation of Reverse Logistics Programs. Oak Brook: Council of Logistics Management.

Tang, H-T. y Lee, Y-M. (2016). The making of sustainable urban development: A synthesis framework. Sustainability, 8(5), 492-520. https://doi.org/10.3390/su8050492

UN-Hábitat (2012). State of the World's Cities 2008/2009. London: United Nations. Recuperado de: https://unhabitat.org/books/ state-of-the-worlds-cities-20082009-harmonious-cities-2/

United Nations (2008). State of the World's Cities 2008/2009. London: United Nations. Recuperado de http://mirror.unhabitat.org/pmss/ listltemDetails.aspx?publicationID $=2562 \& A s$ pxAutoDetectCookieSupport $=1$

United Nations (2014). World Urbanization Prospects. New York: United Nations. Recuperado de http://www.un.org/en/development/ desa/publications/2014-revision-worldurbanization-prospects.html

United Nations (2017). World Population Prospects: The 2017 Revision. New York: United Nations Recuperado de http://www.un.org/ en/development/desa/population/events/ other/21/index.shtml

Watanabe, C. (1994). Industrial ecology and Japan's industrial policy. En D. J. Richardson y A. B. Fullerton (eds.). Industrial Ecology U.S. Japan Perspectives. California: National Academy of Engineering.

Wolman, A. (1965). The metabolism of cit ies. Scientific American, 213(3), 179-190. http://dx.doi.org/10.1038/scientificamerican0965-178

Yeang, K. (1999). Proyectar con la naturaleza: bases ecológicas para el proyecto arquitectónico. Barcelona: Gili.

Yeang, K. y Woo, L. (2010). Dictionary of ecodesign: an illustrated reference. London: Routledge.

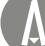





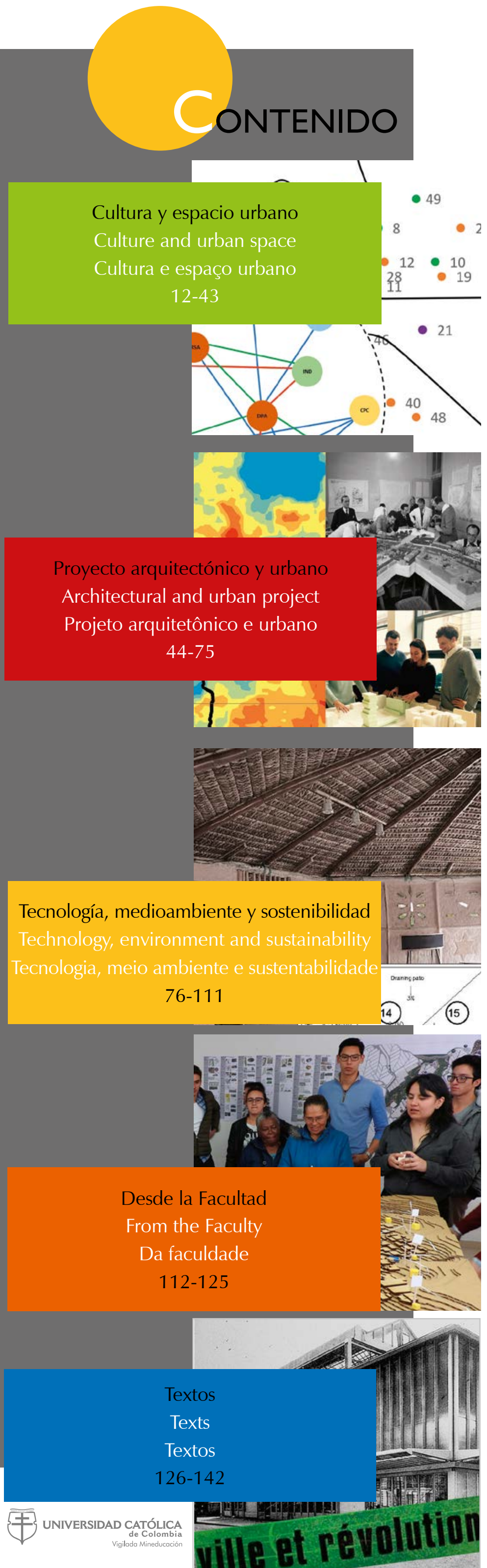

Arquitecturas colectivas y participación como estrategias para la construcción de la ciudad latinoamericana

Myriam Stella Díaz-Osorio

Pág. 3

ES

La caminabilidad en Bogotá: propósitos y condiciones socioespaciales que facilitan y limitan esta experiencia Pablo Páramo

Andrea Burbano

Pág. 12

ES EN

Planificación comunitaria en barrios socialmente

vulnerables. Identificación de los actores sociales en una comunidad

Rafael Alejandro Tavares-Martínez
Jesús Manuel Fitch-Osuna

ES

Pág. 22

Desvanecimiento de la frontera como límite. Imaginario del borde como espacio público físico y virtual

Gabriela Eloísa Muñoz-Torres

Susana Gutiérrez-Luna

Pág. 33

Estudiantes latinoamericanos en el Institut

d'Urbanisme de l'Université de Paris (1923-1941)

$$
\begin{aligned}
& \text { Andrés Ávila-Gómez } \quad \text { Pág. } 44 \\
& \text { ES }
\end{aligned}
$$

Apuntes para el repensamiento de la enseñanza de la Arquitectura. La cuestión epistemológica y la necesidad de una razón ampliada
Juan J. Álvarez-Álvarez
Pág. 57

ES

Equipamientos colectivos: "lugares" de producción de capital social
José Mario Mayorga-Henao
Pág. 68

\section{ES}

Bucle multidisciplinar para la sustentabilidad urbana

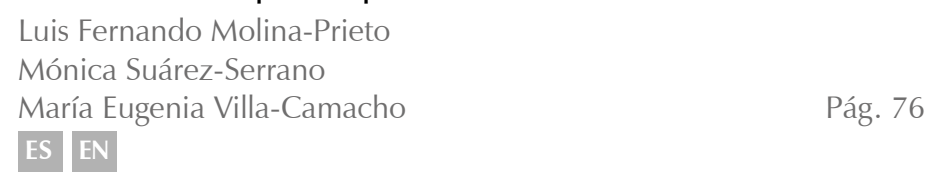

Durabilidad de los materiales naturales de construcción: percepciones de proyectistas, constructores y usuarios en Florianópolis, Brasil

Andrea Salomé Jaramillo-Benavides
Zuleica Maria Patricio-Karnopp
Lisiane Ilha-Librelotto

Pág. 89

\section{ES}

Thermal comfort in buildings for wet processing of coffee

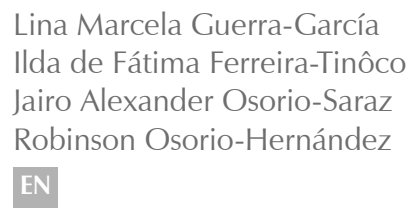

La arquitectura en los barrios: puntos de encuentro entre la academia y el saber popular

Hernando Carvajalino-Bayona

Pág. 112 ES

Arquitectura, modernidad, modernización

$$
\begin{aligned}
& \text { Jean-Louis Cohen } \\
& \text { Traductores } \\
& \text { Andrés Avila-Gómez. } 126 \\
& \text { Diana Carolina Ruiz } \\
& \text { ES }
\end{aligned}
$$


Arquitecturas colectivas y participación como estrategias para la

Arquiteturas coletivas e participação como estratégias para construir a cidad latino-americana

\section{Stella Díaz-Osorio}

La caminabilidad en Bogotá: propósitos y condiciones socioespaciales que facilitan y limitan esta experiencia

The Walkability of Bogotá: purposes and socio-spatial conditions that facilitate and limit this experience

A caminhabilidade em Bogotá: propósitos e condições socioespaciais que facilitam e limitam essa experiência

\section{Andrea Burbano}

Planificación comunitaria en barrios socialmente vulnerables.

Identificación de los actores sociales en una comunidad

Community planning in socially vulnerable neighborhoods.

Identification of social actors in a community

Planejamento comunitário em bairros socialmente vulneráveis.

Identificação dos atores sociais em uma comunidade

Rafael Alejandro Tavares-Martínez

esús Manuel Fitch-Osuna

Desvanecimiento de la frontera como límite. Imaginario del borde como espacio público físico y virtual

$m$

迹

Durabilidad de los materiales naturales de construcción: percepciones de proyectistas, constructores y usuarios en Florianópolis, Brasil

Durability of natural building materials: Perceptions of designers, builders, and users in Florianópolis, Brazil

Durabilidade dos materiais naturais de construção: percepções de projetistas, construtores e usuários em Florianópolis, Brasil

\section{Zuleica Maria Patricio-Karnopp}

Lisiane Ilha-Librelotto

Thermal comfort in buildings for wet processing of coffee

\section{Confort térmico en edificaciones para procesamiento húmedo de café}

Conforto térmico em instalaçōes para processamento úmido de café

\section{Ida de Fátima Ferve-Tartióco}

airo Alexander Osorio-Saraz

Robinson Osorio-Hernandez

La arquitectura en los barrios: puntos de encuentro entre la academia y el saber popular

Architecture in neighborhoods: meeting points between academia and popular knowledge

A arquitetura nos bairros: pontos de encontro entre a academia e o saber popular Hernando Carvajalino-Bayona

\section{Arquitectura, modernidad, modernización}

Architecture, modernity, modernization

Arquitetura, modernidade, modernização
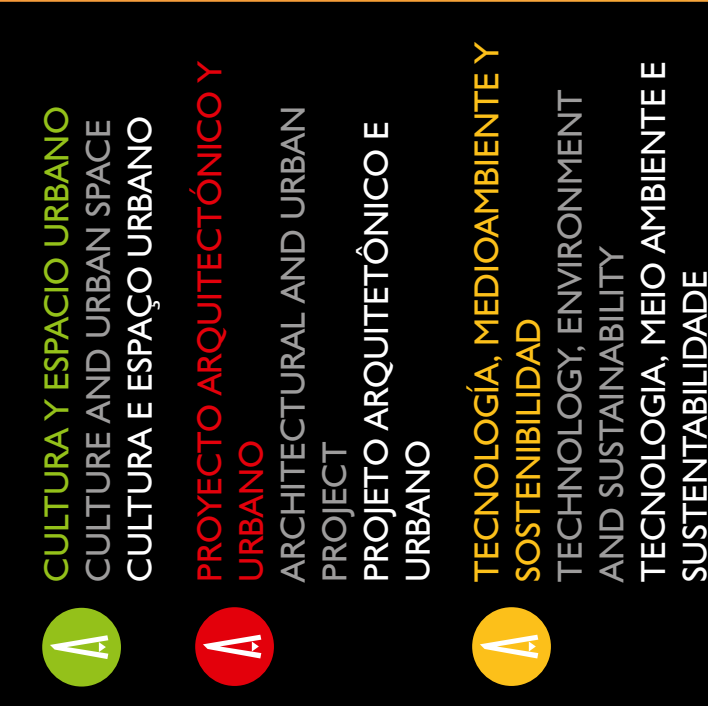

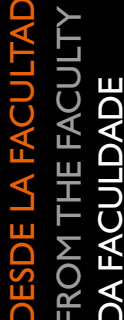

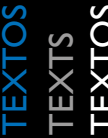
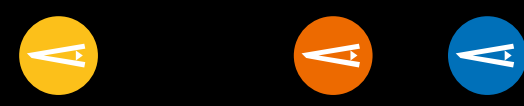

1) Clarivate

publind

Clarivate
Analytics

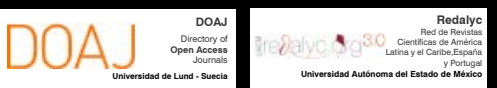

n.

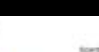

REDIB

EBSCO

cis

latindex unmoxom

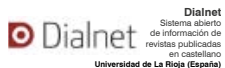

LatinREV

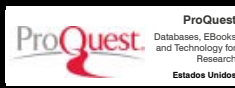

MIคR

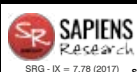

Goosin

Google

ARLA

hi. https://www.mendeley.com/profles/revista-de-arquitectura-bogot/

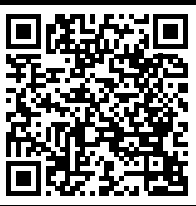

ISSN: 1657-0308 